\title{
Article \\ Critical View on Buffer Layer Formation and Monolayer Graphene Properties in High-Temperature Sublimation
}

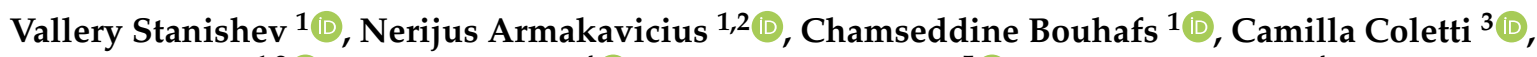 \\ Philipp Kühne ${ }^{1,2}{ }^{\mathbb{D}}$, Ivan G. Ivanov ${ }^{4}\left(\mathbb{D}\right.$, Alexei A. Zakharov ${ }^{5} \mathbb{D}$, Rositsa Yakimova ${ }^{4}$ and Vanya Darakchieva ${ }^{1,2, *}(\mathbb{D}$ \\ 1 Terahertz Materials Analysis Center, Department of Physics, Chemistry and Biology, IFM, Linköping \\ University, 58183 Linköping, Sweden; vallery.stanishev@liu.se (V.S.); nerijus.armakavicius@liu.se (N.A.); \\ cebouhafs@gmail.com (C.B.); philipp.kuhne@liu.se (P.K.) \\ 2 Center for III-Nitride Technology C3NiT-Janzén, Department of Physics, Chemistry and Biology, IFM, \\ Linköping University, 58183 Linköping, Sweden \\ 3 Center for Nanotechnology Innovation @NEST, Istituto Italiano di Tecnologia, Piazza S. Silvestro, 12, \\ 56127 Pisa PI, Italy; Camilla.Coletti@iit.it \\ 4 Department of Physics, Chemistry and Biology, IFM, Linköping University, 58183 Linköping, Sweden; \\ ivan.gueorguiev.ivanov@liu.se (I.G.I.); rositsa.yakimova@liu.se (R.Y.) \\ 5 MaxLab, Lund University, S-22100 Lund, Sweden; alexei.zakharov@maxiv.lu.se \\ * Correspondence: vanya.darakchieva@liu.se
}

\section{check for}

updates

Citation: Stanishev, V.;

Armakavicius, N.; Bouhafs, C.;

Coletti, C.; Kühne, P.; Ivanov, I.G.;

Zakharov, A.A.; Yakimova, R.;

Darakchieva, V. Critical View on

Buffer Layer Formation and

Monolayer Graphene Properties in

High-Temperature Sublimation. Appl.

Sci. 2021, 11, 1891. https://doi.org/

10.3390/app11041891

Academic Editor: Vasili Perebeinos

Received: 31 December 2020

Accepted: 13 February 2021

Published: 21 February 2021

Publisher's Note: MDPI stays neutral with regard to jurisdictional claims in published maps and institutional affiliations.

Copyright: (c) 2021 by the authors Licensee MDPI, Basel, Switzerland. This article is an open access article distributed under the terms and conditions of the Creative Commons Attribution (CC BY) license (https:/ / creativecommons.org/licenses/by/ $4.0 /)$.

\begin{abstract}
In this work we have critically reviewed the processes in high-temperature sublimation growth of graphene in Ar atmosphere using closed graphite crucible. Special focus is put on buffer layer formation and free charge carrier properties of monolayer graphene and quasi-freestanding monolayer graphene on $4 \mathrm{H}-\mathrm{SiC}$. We show that by introducing $\mathrm{Ar}$ at higher temperatures, $T_{\mathrm{Ar}}$, one can shift the formation of the buffer layer to higher temperatures for both $n$-type and semi-insulating substrates. A scenario explaining the observed suppressed formation of buffer layer at higher $T_{\mathrm{Ar}}$ is proposed and discussed. Increased $T_{\mathrm{Ar}}$ is also shown to reduce the $s p^{3}$ hybridization content and defect densities in the buffer layer on $n$-type conductive substrates. Growth on semi-insulating substrates results in ordered buffer layer with significantly improved structural properties, for which $T_{\text {Ar }}$ plays only a minor role. The free charge density and mobility parameters of monolayer graphene and quasi-freestanding monolayer graphene with different $T_{\mathrm{Ar}}$ and different environmental treatment conditions are determined by contactless terahertz optical Hall effect. An efficient annealing of donors on and near the $\mathrm{SiC}$ surface is suggested to take place for intrinsic monolayer graphene grown at $2000{ }^{\circ} \mathrm{C}$, and which is found to be independent of $T_{\mathrm{Ar}}$. Higher $T_{\mathrm{Ar}}$ leads to higher free charge carrier mobility parameters in both intrinsically $n$-type and ambient $p$-type doped monolayer graphene. $T_{\mathrm{Ar}}$ is also found to have a profound effect on the free hole parameters of quasi-freestanding monolayer graphene. These findings are discussed in view of interface and buffer layer properties in order to construct a comprehensive picture of high-temperature sublimation growth and provide guidance for growth parameters optimization depending on the targeted graphene application.
\end{abstract}

Keywords: epitaxial graphene on $\mathrm{SiC}$; buffer layer; quasi-free-standing graphene; monolayer graphene; high-temperature sublimation; terahertz optical Hall effect; free charge carrier properties

\section{Introduction}

Epitaxial graphene on $\mathrm{SiC}$ substrates [1-4] holds promise for myriad of future electronic and sensing applications [5-9]. In particular, on the Si-face of SiC, the number of graphene layers can be well controlled and uniform monolayer graphene (MLG) can be obtained. Epitaxial graphene grown in ultra-high vacuum (UHV) on Si-face SiC consists of small domains with a typical size of 200-500 nm [10-15]. In such instances the surface roughens during the graphitization even when growth starts from an atomically-flat surface. If the graphitization is performed in argon (Ar) atmosphere, smoother surface and 
large-size MLG domains can be obtained [1,2,15]. However, small inclusions of bi-layer graphene (BLG) are typically present, most often formed on the step edges (due to the small miscut of nominally on-axis wafers) or in association with surface defects $[15,16]$. Hydrogen pre-treatment has widely been used to provide step-like surface morphology with atomically flat terraces and typical step height of $0.75 \mathrm{~nm}$. Consequently, BLG always forms on the step edges of hydrogen etched $\mathrm{SiC}$ and giant step bunching is observed in the graphitization process $[2,17]$. The two layers in the BLG are AB-stacked, hence possessing a parabolic band structure in contrast to the linearly dispersing bands (Dirac cones) at the K points of the first Brillouin zone of MLG. As a result, BLG inclusions may degrade significantly the transport properties of graphene on the $\mathrm{Si}$-face of $\mathrm{SiC}$ and limit its applications $[18,19]$.

Several approaches dispensing with $\mathrm{H}$ etching have been explored to eliminate giant step bunching. For example, we have shown that high-temperature sublimation $(T>$ $1800{ }^{\circ} \mathrm{C}$ ) in Ar atmosphere in closed graphite crucible delivers wafer-scale MLG with negligible BLG inclusions and without hydrogen pre-treatment $[1,15,20-24]$. Other openreactor strategies involve pre-conditioning of the $\mathrm{SiC}$ wafer by annealing in $\mathrm{Ar}$ and/or use of polymer layer, which enables smooth and uniform BLG-free MLG $[4,17,25]$.

Formation of MLG on the $\mathrm{Si}$-face $\mathrm{SiC}$ is preceded by consecutive surface reconstructions as the wafer is heated up [26]. The surface undergoes reconstruction from the Si-enriched $(3 \times 3)$ phase to the C-enriched $(6 \sqrt{3} \times 6 \sqrt{3})$-R $30^{\circ}$ phase. The latter phase is often called "buffer layer" or "zero-layer" graphene because it has the same honeycomb lattice structure as graphene. About $1 / 3$ of the $C$ atoms in this initial layer are covalently bound to the $\mathrm{SiC}$ surface and thus the buffer layer is devoid of the electronic properties of graphene [27]. Hydrogen intercalation may be employed to decouple the buffer layer from the substrate turning it into quasi-free-standing (QFS) MLG as the former covalent bonds are broken and the $\mathrm{Si}$ dangling bonds at a $\mathrm{SiC}$ surface are saturated with hydrogen $[27,28]$.

In UHV conditions the surface reconstructions up to the $(6 \sqrt{3} \times 6 \sqrt{3})-\mathrm{R} 30^{\circ}$ phase occur in the temperature range of $800-1200{ }^{\circ} \mathrm{C}$ [29]. Upon heating to a higher temperature, the buffer layer decouples from the $\mathrm{SiC}$ to form a graphene sheet and another buffer layer forms underneath. Tropm and Hannon [26] have shown that the temperature range within which the surface reconstructions occurs can be shifted up by as much as $200^{\circ} \mathrm{C}$ in comparison to the case of an ultrahigh vacuum by increasing the Si background pressure to $\sim 8 \times 10^{-7}$ Torr using disilane. Ar atmosphere efficiently enhances the Si pressure at the substrate surface since Ar atoms act as a diffusion barrier that limits the Si desorption from the surface. As a result, in Ar atmosphere graphene starts to form at higher temperatures as compared to growth in UHV. It has been shown that in an open Ar atmosphere with a pressure of $\sim 900$ mbar graphene starts to form at temperatures above $1550{ }^{\circ} \mathrm{C}$ and the buffer layer forms between $1400{ }^{\circ} \mathrm{C}$ and $1550{ }^{\circ} \mathrm{C}[2,4]$.

Forming the buffer layer at higher temperature has been theoretically suggested to be the key to grow high-quality graphene [30]. Experimentally it has also been shown that forming a smooth buffer layer at a temperature of $T \simeq 1400{ }^{\circ} \mathrm{C}$ prevents giant step bunching and consequently it is possible to obtain a smooth surface covered with uniform MLG [17] even on wafers with a large miscut angle of $0.37^{\circ}$ [4]. Introducing Ar at different temperatures during the graphitization process may provide an alternative pathway to influence the phase transition temperature between different surface reconstructions, and hence enable the growth of smooth MLG without the need of special pre-treatment. However, this approach has not been explored despite the intense investigation of buffer layer properties and optimization [4,31-34].

In this work, we report a comprehensive study of the effect of introducing Ar at different temperatures on the buffer layer formation and its properties in high-temperature sublimation for both $n$-type doped and high-purity semi-insulating (SI) $4 \mathrm{H}-\mathrm{SiC}$. The free charge carrier density and mobility parameters of the corresponding MLG and QFS-MLG are determined for different environmental conditions and discussed. A combined analysis of free charge carrier and structural properties provides insights into the graphitization 
processes in an enclosed environment and basis to design growth strategies depending on graphene targeted application.

\section{Experimental Details}

Buffer and MLG samples were prepared on the Si-face (0001) of on-axis SI and $n$-type doped $4 \mathrm{H}-\mathrm{SiC}$ substrates (Cree, Inc., Durham, NC, USA) by high-temperature sublimation in Ar atmosphere [35] using the sublimation growth facilities at Linköping University. The thickness and miscut angle of the SI and $n$-type doped wafers were $360 \mu \mathrm{m}$ and $0.09^{\circ}$, and $340 \mu \mathrm{m}$ and $0.05^{\circ}$, respectively. The substrates were chemical-mechanical polished (CMP) on the Si-face and optically polished on the C-face. Samples with different sizes of $10 \mathrm{~mm} \times 7 \mathrm{~mm}, 10 \mathrm{~mm} \times 10 \mathrm{~mm}$ or $15 \mathrm{~mm} \times 10 \mathrm{~mm}$ were fabricated. The substrates were first cleaned with acetone and ethanol, followed by the standard RCA1 and RCA2 cleaning procedures. Prior to transfer into the growth chamber, the substrates were treated with a hydrofluoric acid solution to remove the native oxide on the surface.

A graphite crucible with a closed inner cavity has been designed with the Virtual Reactor software (http:/ / www.str-soft.com/products/Virtual_Reactor/ (accessed on 1 February 2021)) to provide uniform (within $\sim 0.5^{\circ} \mathrm{C}$ ) temperature distribution over 2-inch diameter wafer. The inner cavity design was optimized to minimize the lateral temperature variation resulting in a relatively complex shape. A sketch of the crucible is shown in Figure 1. A special graphite holder is used to position the $\mathrm{SiC}$ substrate in the crucible cavity. The crucible was placed into thermally-isolating porous graphite insulation and loaded into the growth chamber. The chamber is pumped down to vacuum level of $\sim 10^{-6}$ mbar and the crucible was inductively heated. Initially, the temperature is ramped up in vacuum at a rate of $\sim 16^{\circ} \mathrm{C}$ per min until the crucible temperature, measured with pyrometer on its surface, has reached $1300^{\circ} \mathrm{C}$. During this initial temperature ramp-up, Ar gas with pressure $P_{\mathrm{Ar}}=850$ mbar was introduced into the chamber when the crucible temperature, $T_{\mathrm{Ar}}$, was between $640{ }^{\circ} \mathrm{C}$ and $1300{ }^{\circ} \mathrm{C}$. At the moment $\mathrm{Ar}$ was introduced the typical vacuum level was $\sim 5 \times 10^{-5} \mathrm{mbar}$ and it took about $5 \mathrm{~min}$ for the Ar pressure to reach $P_{\mathrm{Ar}}=850 \mathrm{mbar}$. During this time the temperature typically increased by about $100^{\circ}$. Above $1300^{\circ} \mathrm{C}$, the temperature ramp-up continues at an increased rate of $\sim 70{ }^{\circ} \mathrm{C}$ per min until the targeted growth temperature, $T_{\mathrm{gr}}$, is reached. The temperature is then kept constant for $0 \mathrm{~min}$ or $5 \mathrm{~min}$, which we refer to as growth time, $t_{\mathrm{gr}}$. During this final temperature ramp-up, $P_{\mathrm{Ar}}$ slightly increased to $P_{\mathrm{Ar}}=880 \mathrm{mbar}$. Once the growth is finished, the inductive heating is switched off and the sample cools down passively at a rate of $\sim 65{ }^{\circ} \mathrm{C}$ per min. The MLG and buffer layer samples were grown at $T_{\mathrm{gr}}=2000{ }^{\circ} \mathrm{C}$ and $T_{\mathrm{gr}}=1600^{\circ} \mathrm{C}$, respectively. The growth conditions for all samples are listed in Table 1 .

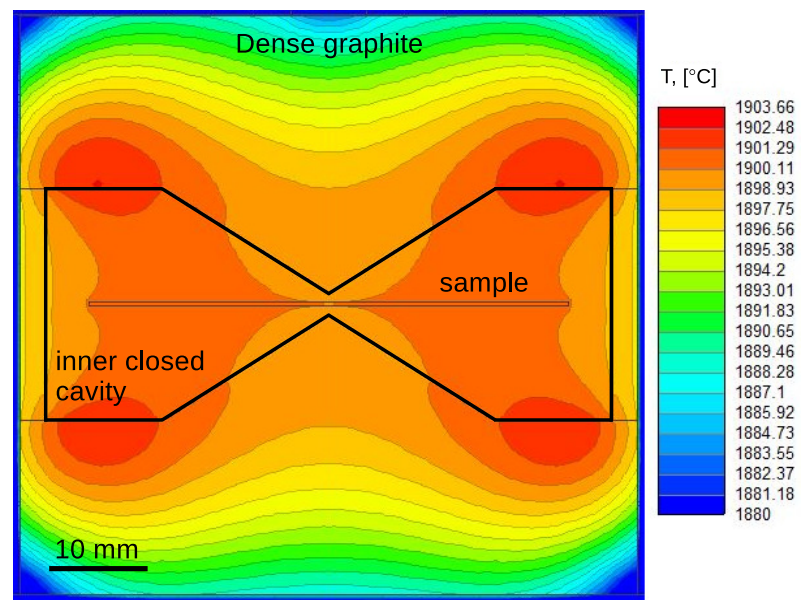

Figure 1. A schematic of the crucible with the distribution of the temperature overplotted. Note that the $\mathrm{SiC}$ substrate is placed within a tightly closed inner cavity and it is completely surrounded by graphite. 
Table 1. Growth conditions of the samples studied in this work: $T_{\mathrm{Ar}}, T_{\mathrm{gr}}$ and $t_{\mathrm{gr}}$ of buffer layer (BL), monolayer graphene (MLG) and quasi-free-standing (QFS)-MLG grown on $n$-type and semiinsulating (SI) substrates.

\begin{tabular}{cccc}
\hline Sample & $T_{\text {Ar }}\left[{ }^{\circ} \mathbf{C}\right]$ & $T_{\text {gr }}\left[{ }^{\circ} \mathbf{C}\right]$ & $t_{\text {gr }}[\mathbf{m i n}]$ \\
\hline \multicolumn{3}{c}{$n$-type $4 \mathrm{H}-\mathrm{SiC}$} & 0 \\
\hline BL1 & 800 & 1600 & 0 \\
BL2 & 900 & 1600 & 0 \\
BL3 & 1150 & 1600 & 0 \\
BL4 & 1300 & 1600 & 0 \\
\hline MLG0 & 800 & 2000 & 0 \\
\hline BL5 & & SI 4H-SiC & 0 \\
\hline BL6 & 800 & 1600 & 0 \\
\hline MLG1 & 1300 & 2000 & 0 \\
MLG2 & 640 & 2000 & 5 \\
MLG3 & 800 & 2000 & 0 \\
\hline QFS-MLG1 & 1300 & 1600 & 0 \\
QFS-MLG2 & 640 & 1600 & 0 \\
QFS-MLG3 & 800 & 1800 & \\
\hline
\end{tabular}

Micro-reflectance and micro-Raman scattering spectroscopy ( $\mu$-RS) maps were measured using the set-up described in Ref. [36]. A diode-pumped semiconductor laser with a wavelength of $532 \mathrm{~nm}$ (photon energy $E_{\mathrm{L}}=2.33 \mathrm{eV}$ ) was used for the excitation. The full-width at half-maximum (FWHM) of the focused laser spot is $\sim 0.4 \mu \mathrm{m}$ using a $100 \times$ objective. Typically, $30 \times 30 \mu \mathrm{m}^{2}$ reflectance maps with step sizes of $0.3 \mu \mathrm{m}$ were measured at different locations of the sample. The typical size of the Raman maps was $10 \times 10 \mu \mathrm{m}^{2}$. For each Raman spectrum, the micro-reflectance was also simultaneously measured. To obtain clean Raman spectra of MLG and buffer layers, a Raman spectrum of a bare $4 \mathrm{H}-\mathrm{SiC}$ substrate was subtracted. Furthermore, all Raman spectra are normalized to the $4 \mathrm{H}-\mathrm{SiC}$ substrate.

The surface morphology of the MLG and buffer layers was characterized by tapping mode atomic force microscopy (AFM) (Veeco Dimension 3100). Microprobe low-energy electron diffraction ( $\mu$-LEED), low energy electron microscopy (LEEM), X-ray photoelectron emission microscopy (XPEEM) and micro-focused X-ray photoelectron spectroscopy (microXPS) were used to investigate the structural properties and chemical composition of the buffer layer samples. The experiments were performed using the ELMITEC-LEEM III instrument at the I311 beamline of the MAX-Lab synchrotron radiation facility in Lund, Sweden.

Contactless terahertz (THz) cavity-enhanced (CE) optical Hall effect (OHE) measurements were performed for the determination of graphene-free charge carrier properties using the custom-built ellipsometry instrumentation at the THz Materials Analysis Center [37]. The OHE describes the magnetic field induced optical birefringence generated by free charge carriers under the influence of the Lorentz force, and can be measured by Mueller matrix ellipsometry [38]. The CE-OHE measurements were performed at room temperature by placing the sample on either of the two sides of a permanent neodymium magnet with a field strength of $B=0.548 \mathrm{~T}$ and an external cavity of $\sim 100 \mu \mathrm{m}$ [39]. Insitu environmental control gas cell was employed to measure the samples in different gases and relative humidity (RH) [37,40]. Mueller Matrix data collected at magnetic fields $B=+0.548 \mathrm{~T}$ and $B=-0.548 \mathrm{~T}$ and their differences were simultaneously analyzed using a stratified optical model with parameterized model dielectric functions (MDFs) assigned to each layer, following the methodology described in Ref. [38]. The model consists of a perfect mirror (magnet), air gap, $4 \mathrm{H}-\mathrm{SiC}$ substrate and an MLG or a QFS-MLG layer. The dielectric function of $4 \mathrm{H}-\mathrm{SiC}$ was first determined from measurements of a bare substrate. 
The substrate MDF parameters were then kept fixed during the analysis of the graphene samples. The MDF of graphene was described by Drude contribution in the presence of magnetic field $[37,38]$. The free charge carrier mobility $\mu$ and sheet density $N_{\mathrm{s}}$ of graphene were determined by non-linear least-squares fit of the calculated Mueller matrix data to the experimental data. The effective mass $m^{*}$ was parametrized as $m^{*}=\sqrt{\left(h^{2} N_{\mathrm{s}}\right) /\left(4 \pi v_{\mathrm{F}}^{2}\right)}$ following Ref. [41], where $v_{\mathrm{F}}=1.02 \times 10^{6} \mathrm{~m} \mathrm{~s}^{-1}$ is the Fermi velocity and $N_{\mathrm{s}}$ is the carrier sheet density.

\section{Results and Discussion}

\subsection{Buffer Layer Formation}

Figure 2 shows $\mu$-Raman spectra of buffer layers on $n$-type $4 \mathrm{H}$-SiC, for which the $\mathrm{Ar}$ gas was introduced at $T_{\mathrm{Ar}}=800{ }^{\circ} \mathrm{C}, 900{ }^{\circ} \mathrm{C}, 1150^{\circ} \mathrm{C}$ and $1300{ }^{\circ} \mathrm{C}$, respectively (BL1-BL4, Table 1). The Raman spectra reveal features in the range of $1200-1700 \mathrm{~cm}^{-1}$, typical for the buffer layer [31,33,42]. The band around $1330 \mathrm{~cm}^{-1}$ appears to be on par in terms of intensity with the band around $1580 \mathrm{~cm}^{-1}$ for all samples. It has been argued that the buffer layer Raman spectrum is not composed of discrete peaks but rather reflects the vibrational density of states [42]. The integrated intensity ratio of the D-band around $1330 \mathrm{~cm}^{-1}\left(D_{\mathrm{BL}}\right)$ and the G-band $1580 \mathrm{~cm}^{-1}\left(\mathrm{G}_{\mathrm{BL}}\right)$ can be used to evaluate the content of $s p^{3}$ hybridization [31] or discuss correlations associated with buffer structure in general [33]. We will come back to this question when comparing buffer layers grown on $n$-type and SI $4 \mathrm{H}-\mathrm{SiC}$. However, what is important to the present discussion is the observation that the intensities of the two bands scale down with increasing $T_{\mathrm{Ar}}$ (see Figure 2). The analysis of the Raman scattering maps shows that the areas with lower reflectivity are associated with lower intensity of the $D_{B L}$ and $G_{B L}$ bands, which we attribute to lower buffer layer coverage. Furthermore, we estimate that the difference of the reflectance between regions that are barely covered with buffer and those with full coverage is $\sim 1 \%$. Hence, reflectance mapping can also be employed to obtain information on the buffer layer uniformity on a large-scale.

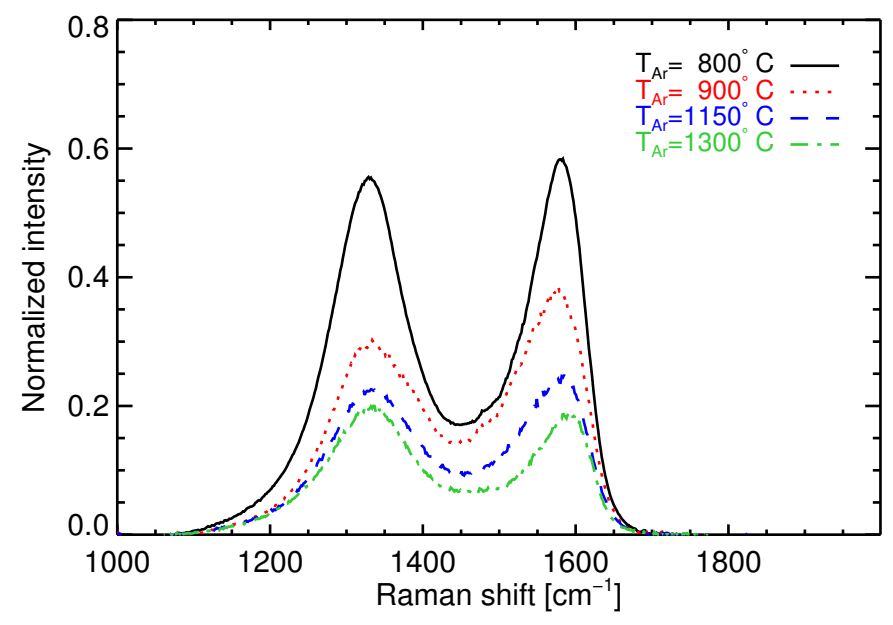

Figure 2. Normalized average $\mu$-Raman scattering spectra obtained over $3 \mu \mathrm{m} \times 3 \mu \mathrm{m}$ maps for the buffer layer samples with different $T_{\mathrm{Ar}}$, indicated in the inset.

The $\mu$-LEED patterns and the respective $30 \mu \mathrm{m} \times 30 \mu \mathrm{m}$ reflectance maps of the buffer layer samples from Figure 2 are shown in Figure 3. The $\mu$-LEED pattern of the sample with $T_{\mathrm{Ar}}=800{ }^{\circ} \mathrm{C}$ (Figure 3a) displays well resolved $\left(6 \sqrt{3} \times 6 \sqrt{3}\right.$ )-R30 $0^{\circ}$ surface reconstruction [11]. The uniform buffer layer coverage, for this sample, is corroborated by LEEM I(V) (not shown) and the reflectance map (Figure 3e), which reveals uniform intensity distribution. A clear buffer layer can also be inferred from the $\mu$-LEED pattern of the buffer layer with $T_{\mathrm{Ar}}=900{ }^{\circ} \mathrm{C}$ (Figure $3 \mathrm{~b}$ ), however, some charging on the surface is observed. The latter could be associated with oxidized $\mathrm{SiC}$ areas not covered by the buffer 
layer. For $T_{\mathrm{Ar}}=1150{ }^{\circ} \mathrm{C}$ even stronger charging is observed in $\mu$-LEED and patches of oxidized Si are identified by XPEEM (Figure 4). A mixture of the buffer layer and oxidized $\mathrm{Si}$ is inferred for this sample. Further confirmation of the suppressed buffer layer formation in the case of $T_{\mathrm{Ar}}=900^{\circ} \mathrm{C}$ and $T_{\mathrm{Ar}}=1150{ }^{\circ} \mathrm{C}$ comes from the respective reflectance maps (Figure 3f,d), which show nonuniform intensity distribution with dark and bright areas. The size of the dark areas with suppressed buffer layer formation increases with increasing $T_{\mathrm{Ar}}$ up to $1150^{\circ} \mathrm{C}$. This sample also shows the highest RMS of $0.7 \mathrm{~nm}$ as compared to 0.35 $\mathrm{nm}$ and $0.5 \mathrm{~nm}$ for the buffer layers with $T_{\mathrm{Ar}}=800{ }^{\circ} \mathrm{C}$ and $T_{\mathrm{Ar}}=900{ }^{\circ} \mathrm{C}$, respectively. Note the resemblance between the XPEEM image (Figure 4) and the reflectance map (Figure 3g). We have previously reported a decrease in the relative reflectance of MLG with respect to the $\mathrm{SiC}$ substrate due to the presence of the oxide layer at the interface [43]. Finally, the sample with $T_{\mathrm{Ar}}=1300^{\circ} \mathrm{C}$ is severely charging and consists mostly of SiC substrate with the buffer layer just beginning to form, as revealed by $\mu$-LEED (Figure $3 \mathrm{~d}$ ). In this case, the reflectance map (Figure $3 \mathrm{~h}$ ) appears quasi-uniform as the buffer layer nuclei are significantly smaller in comparison with the laser spot size.
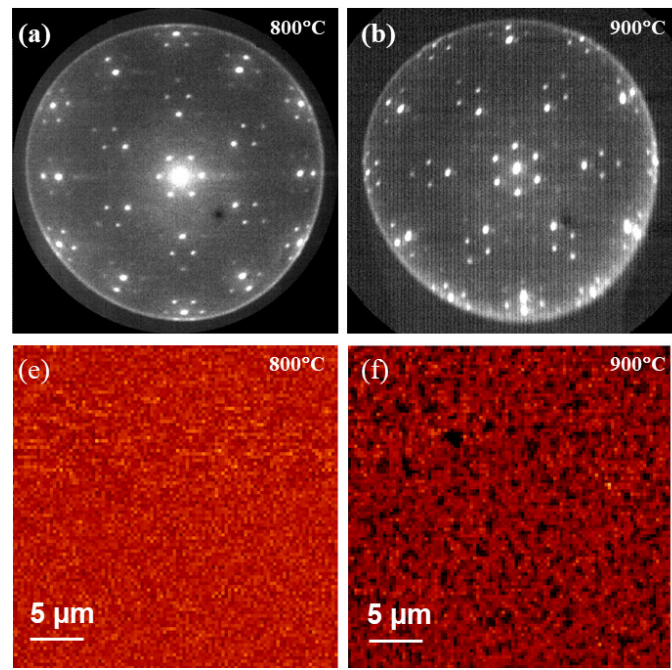
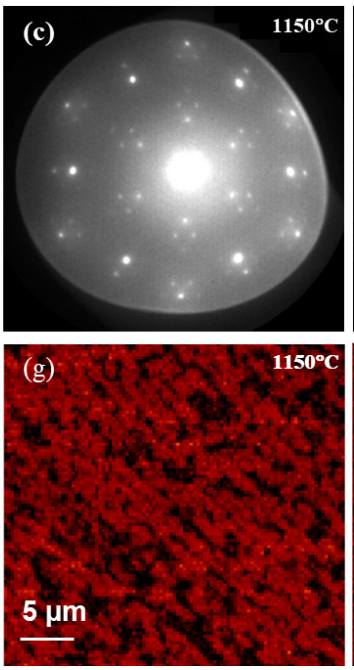

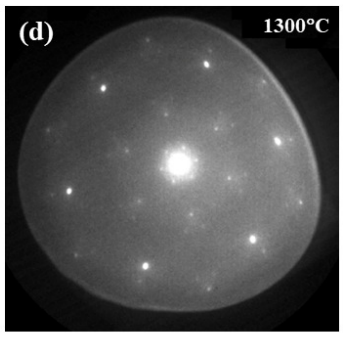

(h) $1300^{\circ} \mathrm{C}$

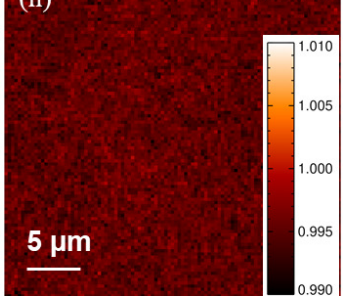

Figure 3. (a-d) Microprobe low-energy electron diffraction ( $\mu$-LEED) patterns taken at electron energy of $50 \mathrm{eV}(\mathbf{a}, \mathbf{b})$ and $40 \mathrm{eV}(\mathbf{c}, \mathbf{d})$ and $(\mathbf{e}-\mathbf{h}) 30 \mu \mathrm{m} \times 30 \mu \mathrm{m}$ normalized reflectance maps of buffer layer samples with $T_{\mathrm{Ar}}=800{ }^{\circ} \mathrm{C}(\mathbf{a}, \mathbf{e}), T_{\mathrm{Ar}}=900{ }^{\circ} \mathrm{C}(\mathbf{b}, \mathbf{f}), T_{\mathrm{Ar}}=1150{ }^{\circ} \mathrm{C}(\mathbf{c}, \mathbf{g})$ and $T_{\mathrm{Ar}}=1300^{\circ} \mathrm{C}$ $(\mathbf{d}, \mathbf{h}) . T_{\mathrm{Ar}}$ are indicated in the up right corner of the respective images. The difference in reflectance between bare substrate and fully covered with buffer layer is $\sim 0.01$.

Based on the Raman scattering spectroscopy, reflectance mapping as well as $\mu$-LEED results, we can conclude that with the increasing temperature at which Ar is introduced, the formation of the buffer layer is suppressed and shifted to a higher temperature. The same trend is also consistently observed when the buffer layers are formed on SI $4 \mathrm{H}-\mathrm{SiC}$ substrates. Our investigations further indicate that the $\mathrm{SiC}$ substrate areas not covered by the buffer layer are oxidized. There are three possible scenarios: (i) oxidation occurs after the buffer layer formation due to ambient exposure when the samples are removed from the reactor; (ii) oxidation occurs after the buffer layer formation during cooling down and (iii) oxidation occurs during the annealing process. Scenario (ii) and (iii) necessitate residual oxygen in the growth system. Oxidation of buffer and MLG samples as a result of residual oxygen has been previously observed for both conventional and high-temperature sublimation growth $[44,45]$. It has been suggested that since the graphitization process does not take place in ultra-high vacuum (oxygen-free) conditions, oxygen may be present as a result of oxygen-containing adsorbates on graphite parts and/or inner walls of the reactor. Different growth strategies to obtain high-quality MLG and/or buffer layer (e.g., for QFS-MLG applications) should be employed depending on whether scenario (i), (ii) or (iii) transpires. 


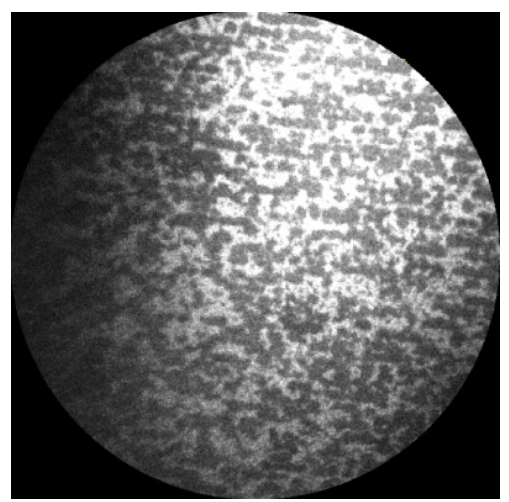

Figure 4. Si 2p oxide X-ray photoelectron emission microscopy (XPEEM) image taken at photon energy of $133 \mathrm{eV}$ and electron energy of $26 \mathrm{eV}$ with $40-\mu \mathrm{m}$ field-of-view for the buffer layer sample with $T_{\mathrm{Ar}}=1150^{\circ} \mathrm{C}$. The bright areas correspond to higher content of $\mathrm{SiO}_{\mathrm{x}}$ but even the dark areas of the image have some oxide component.

In order to elucidate which of the above scenarios takes place, we will discuss in the following the structural evolution of $\mathrm{SiC}$ during the sublimation process in Ar atmosphere. Both $\mathrm{SiC}$ restructuring and surface reconstruction are expected to be affected by the presence of Ar, which influences the gas pressure at the crystal-vapor interface and the mean free path length. Ar atmosphere effectively enhances the Si pressure since it leads to a reduced $\mathrm{Si}$ evaporation rate. The stability of steps on the $\mathrm{SiC}$ surface at a given temperature is also affected by Si pressure since the surface $\mathrm{Si}$ is in equilibrium with the gas phase $\mathrm{Si}$ as well as the bulk SiC. At higher Si pressures higher temperatures are needed to initiate Si decomposition from the terrace [30] and decomposition proceeds rather from the step resulting in smoother surface morphology as compared to ultrahigh vacuum [1,2]. Ar atmosphere also influences the mass transport of various species. Another consequence of the enhanced $\mathrm{Si}$ pressure in $\mathrm{Ar}$ is that $\mathrm{Si}$ depletion close to the $\mathrm{SiC}$ is slowed down and a higher temperature is needed to trigger and complete the buffer layer formation (consequently graphene formation). Indeed, it has been demonstrated that the phase transformation temperatures associated with different surface reconstructions on the Si-face SiC can be shifted by several hundred degrees Celsius by balancing the rate of $\mathrm{Si}$ evaporation with an external flux of Si [26]. In our experiments, when Ar is introduced at $800{ }^{\circ} \mathrm{C}$ the entire surface reconstruction process up to $1600^{\circ} \mathrm{C}$ proceeds under enhanced Si pressure, which should shift the formation of the buffer layer to higher temperatures. In contrast, for $T_{\mathrm{Ar}}=1300^{\circ} \mathrm{C}$ the reconstruction occurs in vacuum up to this temperature and the formation of buffer layer should already take place [29]. We have previously shown that no etching by Ar occurs in the sublimation process in closed crucible [45] as confirmed here by step height distribution (See supplementary information Figure S1). Therefore, one would expect a better developed buffer layer for $T_{\mathrm{Ar}}=1300{ }^{\circ} \mathrm{C}$ compared to $T_{\mathrm{Ar}}=800{ }^{\circ} \mathrm{C}$. Surprisingly, we find the opposite trend from the Raman scattering spectroscopy, reflectance mapping and $\mu$-LEED results. These findings are not compatible with scenarios (i) and (ii) in which oxidation of uncovered areas occurs after buffer layer formation. A potential explanation for the observed suppression of buffer layer formation at higher $T_{\mathrm{Ar}}$ is provided by scenario (iii) in which the observed oxidation occurs during the annealing process.

It has been shown that intermediate $\mathrm{SiO}_{x}$ on the $\mathrm{Si}$-face of $\mathrm{SiC}$ is stable up to a temperature of $1200{ }^{\circ} \mathrm{C}$ and it is difficult to be fully eliminated even at $1400{ }^{\circ} \mathrm{C}$ [46]. Thus, if oxidation occurs during annealing and $\mathrm{Ar}$ is introduced at temperatures higher than $1200{ }^{\circ} \mathrm{C}$ the oxide layer will prevent the buffer layer formation. As the oxide layer starts to gradually be removed above $1200-1400{ }^{\circ} \mathrm{C}$ Ar effectively enhances the $\mathrm{Si}$ gas pressure and suppresses the phase transformation to $(6 \sqrt{3} \times 6 \sqrt{3})$ - $\mathrm{R} 30^{\circ}$ surface reconstruction. As a results after heating up to $1600{ }^{\circ} \mathrm{C}$, the sample with $T_{\mathrm{Ar}}=1300^{\circ} \mathrm{C}$ (BL4) shows only the initial stage of the buffer layer and is mostly uncovered $\mathrm{SiC}$ (Figure 3d). At $T_{\mathrm{Ar}}$ lower than $1200^{\circ} \mathrm{C}$ (BL1, BL2, BL3), Ar reduces the mean free path of oxygen suppressing oxide 
formation and allowing complete (partial) buffer layer formation for $T_{\mathrm{Ar}}=800{ }^{\circ} \mathrm{C}\left(900{ }^{\circ} \mathrm{C}-\right.$ $1150^{\circ} \mathrm{C}$.) We note that no charging or any indication of oxidation is observed in the buffer layer sample with $T_{\mathrm{Ar}}=800{ }^{\circ} \mathrm{C}$, which may be understood in view of the reduced mean free path of oxygen at lower temperatures.

Scenario (iii) has several important implications for the growth strategies to obtain high-quality graphene by high-temperature sublimation. As the buffer layer becomes the first graphene layer upon annealing, forming the buffer layer and, consequently, graphene at higher temperatures should be favorable in terms of surface roughness and uniform restructuring as they affect positively free charge carrier mobility. At the same time, one can argue that if the buffer layer forms at lower temperatures it can be conditioned during the annealing process until the temperature of graphene formation is reached, reducing the density of defects such as vacancies or/and $s p^{3}$-defects. Another interesting question is to compare the properties of QFS-MLG obtained from buffer layers grown using different $T_{\mathrm{Ar}}$ and understand which mechanism has a decisive role. To address these questions we have investigated the free charge carrier properties of MLG and QFS-MLG samples for which the Ar was introduced at different $T_{\mathrm{Ar}}$ (Table 1). The MLG and QFS-MLG were grown on SI substrates in order to reliably measure the free charge carrier properties. Interestingly, a difference between the Raman scattering spectra grown at the same conditions on $n$-type and $\mathrm{SI} 4 \mathrm{H}-\mathrm{SiC}$ is observed.

\subsection{Comparison between Buffer Layers Grown on n-Type and SI $4 \mathrm{H}-\mathrm{SiC}$}

A comparison of the Raman spectra of buffer layers on $n$-type and SI $4 \mathrm{H}-\mathrm{SiC}$ obtained at $T_{\mathrm{Ar}}=800{ }^{\circ} \mathrm{C}$ is presented in Figure 5a. The Raman spectrum of the buffer layer grown on n-type substrate displays $\mathrm{D}_{\mathrm{BL}}$ (around $1330 \mathrm{~cm}^{-1}$ ) and $\mathrm{G}_{\mathrm{BL}}$ (around $1580 \mathrm{~cm}^{-1}$ ) bands with similar intensities. The latter is slightly asymmetric due to a band at around $1530 \mathrm{~cm}^{-1}$ (see also Figure 2). Such Raman spectrum is typical for carbon-rich graphitic clusters bonded to SiC [27] and can be associated with a large degree of disorder [47]. On the other hand, the buffer layer grown at the same conditions but on SI substrates exhibits blue shift of the $\mathrm{D}_{\mathrm{BL}}$ and the $\mathrm{G}_{\mathrm{BL}}$ bands, and the band at around $1530 \mathrm{~cm}^{-1}$ becomes more pronounced. These are typical vibrational characteristics of a well-connected buffer layer domains [4]. Further information about disorder and the content of $s p^{3}$ hybridization can be obtained from the histograms of the $\mathrm{G}_{\mathrm{BL}}$ band position (Figure 6a,c) and the ratios of the $\mathrm{D}_{\mathrm{BL}}$ and $\mathrm{G}_{\mathrm{BL}}$ bands areas, $A_{\mathrm{D}_{\mathrm{BL}}} / A_{\mathrm{G}_{\mathrm{BL}}}$ (Figure $\left.6 \mathrm{~b}, \mathrm{~d}\right)$. The $\mathrm{G}_{\mathrm{BL}}$ band energy changes from $1583 \mathrm{~cm}^{-1}$ to $1606 \mathrm{~cm}^{-1}$ and the $A_{\mathrm{D}_{\mathrm{BL}}} / A_{\mathrm{G}_{\mathrm{BL}}}$ changes from 2.0 to 1.3 comparing the buffer layers grown on $n$-type and SI substrates, respectively. A similar trend is also found for the case of $T_{\mathrm{Ar}}=1300{ }^{\circ} \mathrm{C}$ (Figure 6e,g). According to the amorphization trajectory presented for nano-crystalline graphite in Ref. [48], these changes can be associated with a significant reduction of the $s p^{3}$ hybridization content for the case of the SI $4 \mathrm{H}-\mathrm{SiC}$. The $A_{\mathrm{D}_{\mathrm{BL}}} / A_{\mathrm{G}_{\mathrm{BL}}}$ is further related to the degree of disorder introduced by the presence of $s p^{3}$ defects, which is proportional to the average distance between the defects [47]. Accordingly, the density of defects in the buffer layer grown on the SI substrate is $46 \%$ lower and the crystallite size is 35\% larger. Again, very similar trend is found for the buffer layer with $T_{\mathrm{Ar}}=1300^{\circ} \mathrm{C}$ (Figure 6f,h). The observed differences between the two types of substrates could be understood considering the fact that electron concentration generally enhances thermal conductivity. Hence, temperature variations should occur slower for the SI substrates during the heating up, bringing the graphitization process closer to thermodynamic equilibrium and allowing the formation of a well-connected buffer layer with a lower density of defects. It is interesting to note that the vibrational features of the buffer layer formed underneath MLG, grown at $T_{\mathrm{gr}}=2000{ }^{\circ} \mathrm{C}$ for $0 \mathrm{~s}$, (Figure $5 \mathrm{~b}$ ) become even finer and bear closer resemblance with the buffer vibrational density of states [42]. Note that the spectral features are identical for the buffer layers on conductive and SI substrates. This further highlights the important roles of the carbon-rich environment and the high temperature for the formation of high-quality buffer layer. 

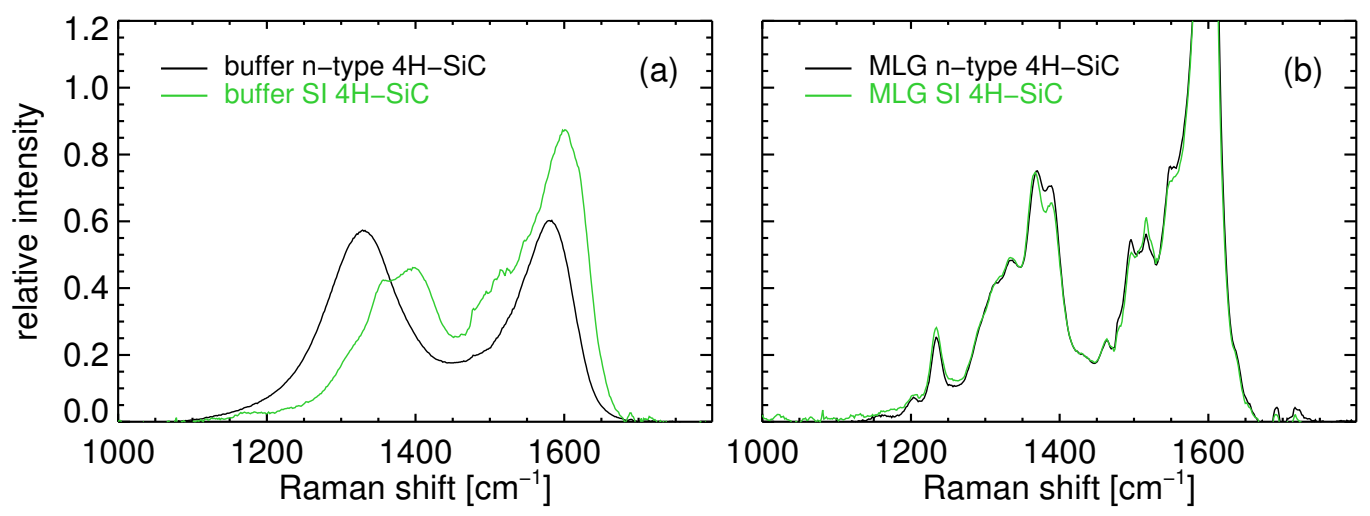

Figure 5. A comparison between the average $\mu$-Raman scattering spectra for buffer layer samples with $T_{\mathrm{Ar}}=800^{\circ} \mathrm{C}$ : (a) on n-type and SI $4 \mathrm{H}-\mathrm{SiC}$, and (b) the buffer layer features in fully-formed MLG at $T_{\mathrm{Gr}}=2000^{\circ} \mathrm{C}$ for $0 \mathrm{~s}$ on $n$-type and SI $4 \mathrm{H}-\mathrm{SiC}$.
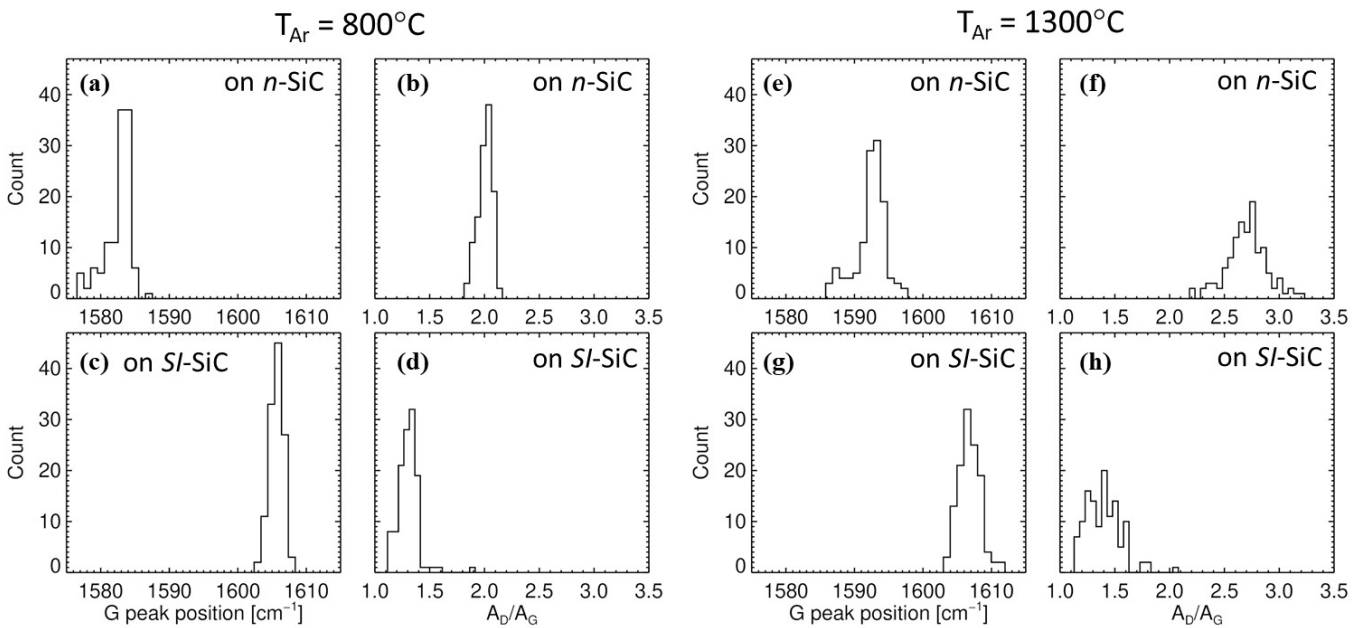

Figure 6. Histograms of the $\mathrm{G}_{\mathrm{BL}}$ band position and the ratio of the $\mathrm{D}_{\mathrm{BL}}$ and $\mathrm{G}_{\mathrm{BL}}$ band areas, $A_{\mathrm{D}_{\mathrm{BL}}} / A_{\mathrm{G}_{\mathrm{BL}}}$, for the buffer layers grown with $T_{\mathrm{Ar}}=800{ }^{\circ} \mathrm{C}(\mathbf{a}-\mathbf{d})$ on $n$-type $(\mathbf{a}, \mathbf{b})$ and SI $(\mathrm{c}, \mathrm{d}) 4 \mathrm{H}-$ $\mathrm{SiC}$; and for the buffer layers grown with $T_{\mathrm{Ar}}=1300{ }^{\circ} \mathrm{C}(\mathbf{e}-\mathbf{h})$ on $n$-type $(\mathbf{e}, \mathbf{f})$ and SI $(\mathbf{g}, \mathbf{h}) 4 \mathrm{H}-\mathrm{SiC}$. The histograms are obtained over Raman maps of $3 \mu \mathrm{m} \times 3 \mu \mathrm{m}$. Three Lorentzian lineshapes centered around $\mathrm{G}_{\mathrm{BL}}$ of $1585-1600 \mathrm{~cm}^{-1}, \mathrm{D}_{\mathrm{BL}}$ of $1330-1530 \mathrm{~cm}^{-1}$ and a band centered at $1340 \mathrm{~cm}^{-1}$ were used for the fitting.

Comparing the buffer layers grown on $n$-type substrates and different $T_{\mathrm{Ar}}$, a moderate blue-shift of the G-like band position for $T_{\mathrm{Ar}}=1300{ }^{\circ} \mathrm{C}$ to $1593 \mathrm{~cm}^{-1}$ with respect to the sample with $T_{\mathrm{Ar}}=800{ }^{\circ} \mathrm{C}\left(1583 \mathrm{~cm}^{-1}\right)$ can be seen (Figure 6a,e). This can be explained by a reduced $s p^{3}$ hybridization content as expected due to the higher temperature at which the reconstruction occurs. At the same time, the $A_{\mathrm{D}_{\mathrm{BL}}} / A_{\mathrm{G}_{\mathrm{BL}}}$ increases from 2.0 to 2.7 (Figure $6 \mathrm{~b}, \mathrm{f}$ ), which could be related to a reduced crystallite size with $30 \%$. This finding is in accordance with our $\mu$-LEED results showing that the buffer layer with $T_{\mathrm{Ar}}=1300{ }^{\circ} \mathrm{C}$ has just begun to form. We now turn our attention to the buffer layers grown with different $T_{\mathrm{Ar}}$ on $\mathrm{SI} 4 \mathrm{H}-\mathrm{SiC}$ substrates. The same trend of suppressed reconstruction with increasing $T_{\mathrm{Ar}}$ is found. In fact, for the case of $T_{\mathrm{Ar}}=1300^{\circ} \mathrm{C}$ heating up to $1600^{\circ} \mathrm{C}$ did not result into a buffer layer formation and heating up to $1800{ }^{\circ} \mathrm{C}$ was needed for a clear buffer layer Raman spectrum to be obtained. Interestingly, the buffer layers grown with $T_{\mathrm{Ar}}=$ $800{ }^{\circ} \mathrm{C}$ and $T_{\mathrm{Ar}}=1300^{\circ} \mathrm{C}$ exhibit very similar $\mathrm{G}_{\mathrm{BL}}$ positions (Figure $6 \mathrm{c}, \mathrm{g}$ ) and $A_{\mathrm{D}_{\mathrm{BL}}} / A_{\mathrm{G}_{\mathrm{BL}}}$ ratios (Figure $6 \mathrm{~d}, \mathrm{~h}$ ), indicating similar $s p^{3}$ hybridization contents and densities of defects. A slightly broader distribution is observed for the case of $T_{\mathrm{Ar}}=1300^{\circ} \mathrm{C}$ for both n-type and $\mathrm{SI} 4 \mathrm{H}-\mathrm{SiC}$ substrates, reflecting a slightly larger variation of the crystallite size. 
Based on these results we can conclude that the temperature at which Ar is introduced has a determining role in the formation of the buffer layer in high-temperature sublimation in closed crucible independently of the $4 \mathrm{H}-\mathrm{SiC}$ substrate conductivity. As a result of an interplay between oxidation and restructuring in Ar atmosphere, the formation of the buffer layer is shifted to higher temperatures for increased $T_{\mathrm{Ar}}$ of $1300{ }^{\circ} \mathrm{C}$. Increasing $T_{\mathrm{Ar}}$ also leads to reduction of $s p^{3}$ hybridization contents and densities of defects on $n$-type $4 \mathrm{H}-\mathrm{SiC}$. However, $\mathrm{T}_{\mathrm{Ar}}$ has a less pronounced effect for SI substrates, where ordered buffer layers form with similar structural properties.

\subsection{Free Charge Carrier Properties of MLG and QFS-MLG}

It is well-known that MLG on $\mathrm{SiC}$ is intrinsically $n$-type doped [49-51]. However, exposure to ambient can cause environmental doping of graphene via an acceptor redox reaction at the surface of the graphene involving various environmental gases $\left(\mathrm{O}_{2}, \mathrm{H}_{2} \mathrm{O}\right.$, and $\mathrm{CO}_{2}$ ), which results in electron withdrawal [52]. Consequently, MLG can exhibit $p$-type conductivity depending on sample history $[24,53]$. We have previously shown that the $\mathrm{THz} \mathrm{OHE}$ is an excellent tool to precisely determine free charge carrier density and mobility parameters of graphene and monitor their in-situ variation under the influence of different gases $[24,37,40,54]$. In order to determine the intrinsic properties of MLG and QFS-MLG, prior to the measurements they were annealed in vacuum $\left(10^{-6} \mathrm{mbar}\right)$ at $1000{ }^{\circ} \mathrm{C}$ and $500{ }^{\circ} \mathrm{C}$, respectively. The annealing temperature was confirmed to not cause deintercalation or any changes in the QFS-MLG structural properties by LEEM, AFM, and $\mu$-LEED. The samples were kept in dry $\mathrm{N}_{2}$ during the measurements and storage. In addition, we have performed measurements after purging with dry $\mathrm{N}_{2}$ for several days and air with RH of $45 \%$ for several hours. Both transient and static measurements were carried out. Finally, the samples were measured after being stored in ambient conditions for several months. We have selected for these investigations samples with the following $T_{\mathrm{Ar}}$ : (i) $T_{\mathrm{Ar}}=800^{\circ} \mathrm{C}$, for which the surface reconstruction happens entirely in Ar atmosphere and that shows completed buffer layer after heating to $T_{\mathrm{gr}}=1600{ }^{\circ} \mathrm{C}(0 \mathrm{~s})$; (ii) $T_{\mathrm{Ar}}=$ $1300{ }^{\circ} \mathrm{C}$, for which the surface reconstruction happens entirely in vacuum, and which needed heating to $T_{\mathrm{gr}}=1800^{\circ} \mathrm{C}$ for the buffer layer to form. Although no indications of surface oxidation were observed for the buffer layer sample with $T_{\mathrm{Ar}}=800^{\circ} \mathrm{C}$, a nanoscale oxidation cannot be excluded. Furthermore, the graphitization process is shifted to higher temperatures in comparison to n-type substrate as pointed out above. We, therefore, included in our investigation MLG and QFS-MLG samples, for which the Ar was introduced at (iii) $T_{\mathrm{Ar}}=640{ }^{\circ} \mathrm{C}$. Growth temperature $T_{\mathrm{gr}}=1600{ }^{\circ} \mathrm{C}$ was employed to produce the buffer layer sample in this case. The QFS-MLG samples were obtained by hydrogen intercalation of the respective buffer layers as described in Ref. [28]. The MLG samples were fabricated using our optimized conditions of $T_{\text {gr }}=2000{ }^{\circ} \mathrm{C}$ for $0 \mathrm{~s}$ growth time, which results in less than $1 \%$ BLG inclusions. The sample with $T_{\mathrm{Ar}}=1300{ }^{\circ} \mathrm{C}$ required a longer growth time of $5 \mathrm{~min}$ for a homogeneous MLG to form leading to increased BLG inclusions of $8 \%$.

Figure 7 shows the free charge carrier density (left panel) and mobility (right panel) of MLG (filled symbols) and QFS-MLG (open symbols) with different $T_{\text {Ar }}$ for different environmental conditions. The mobility parameters were found to be slightly anisotropic in accordance with our recent study [24]. The anisotropy, which is caused by the substrate step edges, does not have any bearing on the results discussed in the current work. Consequently, for brevity we present here the averaged mobility between the parameters determined along and perpendicular to the step edge. The freshly annealed MLG samples show $n$-type conductivity, as expected, with values in the range of $3.9 \times 10^{12} \mathrm{~cm}^{-2}$ to $6.6 \times$ $10^{12} \mathrm{~cm}^{-2}$. Due to the semi-insulating nature of the substrates, the MLG doping should be entirely governed by charge transfer due to surface donor states [55]. All three free electron density values are below the saturation density of n-type doping of MLG of $10^{13} \mathrm{~cm}^{-2}$ [55], indicating successful efficient annealing of donors on and near the SiC surface. The observed differences with $T_{\mathrm{Ar}}$, albeit small, are significantly below the error bar of $0.3 \times$ 
$10^{12} \mathrm{~cm}^{-2}$. Since the MLG with $T_{\mathrm{Ar}}=1300^{\circ} \mathrm{C}$ was obtained for a considerably longer time ( 5 min as compared to $0 \mathrm{~s}$ ) it is tempting to speculate that the longer annealing may have a positive effect on reducing the interface dangling bonds effectively reducing the density of the surface state and leading to a lower free electron density. We have previously shown that purging with $\mathrm{N}_{2}$ (or inert gases) effectively removes the ambient acceptor dopant, which may require up to several days of purging $[37,40]$. The free electron densities in the MLG samples with $T_{\mathrm{Ar}}=640^{\circ} \mathrm{C}$ and $T_{\mathrm{Ar}}=800^{\circ} \mathrm{C}$ after purging in dry $\mathrm{N}_{2}$ for 9-10 days increased slightly to $5.1 \times 10^{12} \mathrm{~cm}^{-2}$ and $7.0 \times 10^{12} \mathrm{~cm}^{-2}$, respectively, remaining below the the saturation density of n-type doping. The electron mobility parameters in these two cases slightly decreased in comparison to the freshly annealed samples, most likely as a result of the slightly increased charge density. The MLG with $T_{\mathrm{Ar}}=1300{ }^{\circ} \mathrm{C}$ shows the opposite behavior with slightly decreased charge density and slightly increased mobility parameter. Overall the purging with dry $\mathrm{N}_{2}$ led to very small changes in the MLG electron density and mobility, which can be considered as the intrinsic free-electron parameters of MLG.
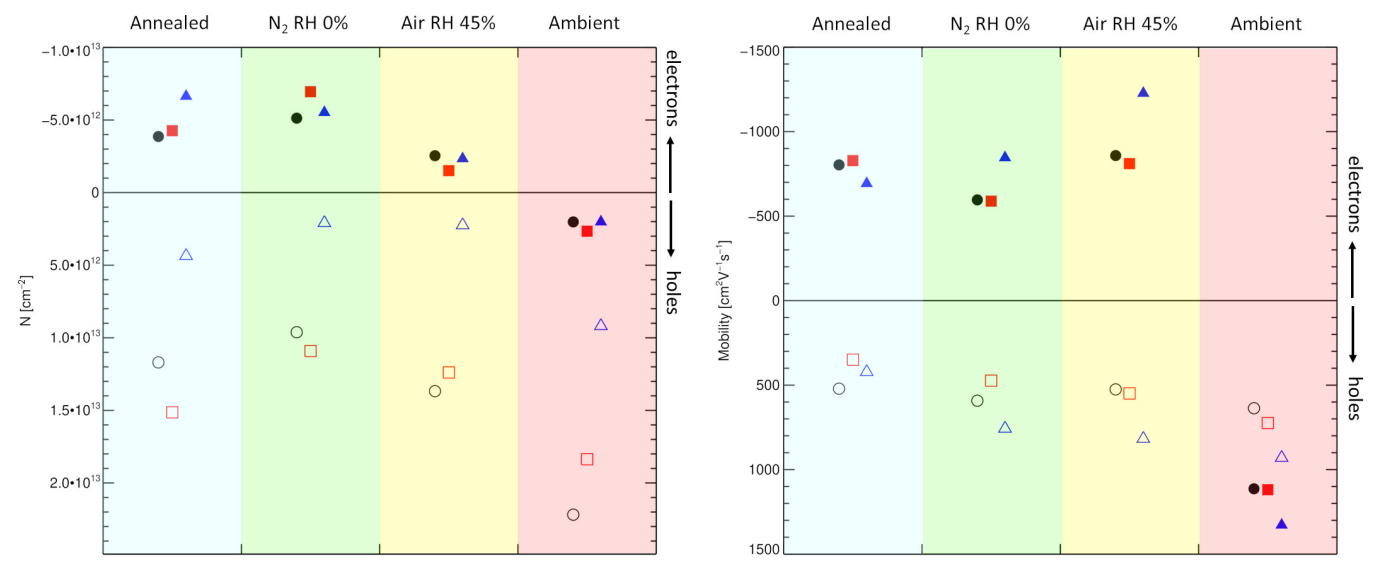

Figure 7. Free charge carrier density (left panel) and mobility (right panel) of MLG (filled symbols) and QFS-MLG (open symbols) with $T_{\mathrm{Ar}}=640{ }^{\circ} \mathrm{C}$ (black circles), $T_{\mathrm{Ar}}=800{ }^{\circ} \mathrm{C}$ (red squares) and $T_{\mathrm{Ar}}=1300{ }^{\circ} \mathrm{C}$ (blue triangles) for different environmental conditions: after annealing in vacuum (Annealed), after being purged with dry $\mathrm{N}_{2}$ for several days $\left(\mathrm{N}_{2} \mathrm{RH} 0 \%\right)$, after being purged with moist air (RH 45\%) for several hours (Air RH 45\%), and after being exposed to the ambient for several months (Ambient).

As expected after purging with moist air ( $\mathrm{RH}$ of $45 \%$ ) the electron density in the MLG samples decreased due to the acceptor redox reaction at the graphene surface. The samples with different $T_{\mathrm{Ar}}$ show very similar electron density of $\sim 2 \times 10^{12} \mathrm{~cm}^{-2}$ after $\sim 20 \mathrm{~h}$ of purging. We have measured the in-situ variations of free charge carrier properties and found that approximately $45 \mathrm{~h}$ purging in moist air are needed to flip the conductivity of MLG from $n$-type to $p$-type with free hole density of $1.4 \times 10^{12} \mathrm{~cm}^{-2}$. Long-term exposure in ambient conditions (several months) leads to only a very small increase of free hole density to $\sim 2 \times 10^{12} \mathrm{~cm}^{-2}$ indicating saturation of p-type ambient doping in MLG. Again, very similar free hole densities are found for the samples with different $T_{\mathrm{Ar}}=1300^{\circ}$. On the other hand, the free charge carrier mobility of the ambient doped MLG with $T_{\mathrm{Ar}}=1300{ }^{\circ} \mathrm{C}$ is more than $50 \%$ larger than the respective values of MLG with $T_{\mathrm{Ar}}=800{ }^{\circ} \mathrm{C}$ and $T_{\mathrm{Ar}}=640{ }^{\circ} \mathrm{C}$. This is true for both the cases of free electrons and free holes (see Figure 7 right panel results for Air $\mathrm{RH} 45 \%$ and Ambient). This finding is very interesting considering that the samples with $T_{\mathrm{Ar}}=640{ }^{\circ} \mathrm{C}$ and $T_{\mathrm{Ar}}=800{ }^{\circ} \mathrm{C}$ have better MLG coverage of $99 \%$ and lower $\mathrm{RMS} \simeq 0.4 \mathrm{~nm}$, compared with the $T_{\mathrm{Ar}}=1300^{\circ} \mathrm{C}$ sample, which has $92 \%$ MLG coverage and $\mathrm{RMS} \simeq 0.75 \mathrm{~nm}$. It was previously suggested that dominant scattering mechanisms at room temperature in graphene on $\mathrm{SiC}$ are the remote interface phonon scattering, as a result of coupling to the polar modes in the substrate, and scattering by impurities [56-58]. Since the MLG samples are grown at the same $T_{\mathrm{gr}}$ and have a similar history we do not 
anticipate a difference in impurity levels. It is thus plausible to suggest that in the MLG with $T_{\mathrm{Ar}}=1300{ }^{\circ} \mathrm{C}$ the interface phonon scattering is reduced as a result of different interface properties. We recall that the buffer layers grown at different $T_{\mathrm{Ar}}$ on SI substrates exhibit very similar $s p^{3}$ contents and defect densities (Figure 6). Furthermore, the Raman scattering spectral features associated with the buffer layer in the respective MLG samples with different $T_{\mathrm{Ar}}$ are practically identical. Hence, the reduced interface phonon scattering is likely a result of a different interface between MLG and the buffer layer rather than between buffer layer and SiC substrate. This suggestion is further supported by the similar free charge carrier density in the ambient doped MLG with different $T_{\text {Ar }}$ indicating similar surface state densities. To gain further insight into the origin of the different interface properties between MLG and the buffer layers we turn now our attention to the free charge carrier properties of the QFS-MLG samples.

In QFS-MLG the intercalated hydrogen saturates the Si dangling bonds passivating the interface donor states. Consequently, QFS-MLG exhibits $p$-type doping induced by the spontaneous polarization of the $\mathrm{SiC}$ substrate $[28,59,60]$. The resulting free hole density in QFS-MLG on SI 4H-SiC was reported to be $8.6 \times 10^{12} \mathrm{~cm}^{-2}$ as determined by angular resolved photo-electron spectroscopy (ARPES) [60]. As expected our freshly annealed QFS-MLG samples show $p$-type conductivity (see Figure 7 left panel). We find very similar free hole densities in the QFS-MLG with $T_{\mathrm{Ar}}=640^{\circ} \mathrm{C}$ and $T_{\mathrm{Ar}}=800{ }^{\circ} \mathrm{C}$ of $1.2 \times 10^{13} \mathrm{~cm}^{-2}$ and $1.5 \times 10^{13} \mathrm{~cm}^{-2}$, respectively. These values are slightly higher than the free hole density expected from pure polarization doping [60]. It is possible that some residual ambient doping is present as the annealing temperature for the QFS-MLG samples was relatively low in order to prevent deintercalation. Purging in dry $\mathrm{N}_{2}$ for several days lead to a small reduction of the free hole density in these two samples to $\sim 1.0 \times 10^{13} \mathrm{~cm}^{-2}$, which is suggested to be the intrinsic value for our QFS-MLG resulting from polarization doping. We consider this to be a good agreement with the previously reported value of 8.6 $\times 10^{12} \mathrm{~cm}^{-2}$ [60] given the different experimental techniques used in the two works and the various fitting parameters employed to deduce the free hole concentration from ARPES. Both the freshly annealed and the dry $\mathrm{N}_{2}$ purged QFS-MLG with $T_{\mathrm{Ar}}=1300{ }^{\circ} \mathrm{C}$ show significantly lower free hole density of $4.4 \times 10^{12} \mathrm{~cm}^{-2}$ and $2.1 \times 10^{12} \mathrm{~cm}^{-2}$, respectively. According to the polarization doping model, the negative pseudo-polarization charge, which is a constant parameter for the $4 \mathrm{H}-\mathrm{SiC}$, is balanced by the free holes in the QFS-MLG and the positive space charge in the substrate depletion layer [60]. Since the bulk doping in the SI substrate is the same for all three samples leading to a similar positive space charge in the substrate depletion layer, the observed lower free hole density in QFS-MLG with $T_{\text {Ar }}=1300{ }^{\circ} \mathrm{C}$ indicates the presence of donor surface states. As noted earlier, the buffer layers grown at different $T_{\mathrm{Ar}}$ on SI substrates exhibit very similar $s p^{3}$ contents and defect densities (Figure 6). We also confirmed by $\mu$-Raman scattering spectroscopy mapping that no structural changes occur as a result of the intercalation process. Recall that in comparison to lower $T_{\mathrm{Ar}}$ the buffer layer with $T_{\mathrm{Ar}}=1300{ }^{\circ} \mathrm{C}$ is incomplete. We speculate that this incomplete buffer layer formation may be the cause of the surface donor states, likely dangling bonds. Interestingly, purging with moist air ( $\mathrm{RH} 45 \%$ ) for $\sim 18 \mathrm{~h}$ leads to small increase of free hole density in QFS-MLG with $T_{\mathrm{Ar}}=800^{\circ} \mathrm{C}$ and $T_{\mathrm{Ar}}=640^{\circ} \mathrm{C}$ while for $T_{\mathrm{Ar}}=1300^{\circ} \mathrm{C}$ the hole density remains unchanged. This can be potentially explained by the above-mentioned scenario since the purge with moist air has different effects: for the polarization doped QFS-MLG it leads to chemical acceptor doping of graphene while for the sample with $T_{\mathrm{Ar}}=1300{ }^{\circ} \mathrm{C}$ it leads to passivation of surface donor states. The two processes will naturally have different dynamics. This proposal is also consistent with the results for prolonged exposure to ambient. The free hole density in QFS-MLG with $T_{\mathrm{Ar}}=1300{ }^{\circ} \mathrm{C}$ increases to $9.2 \times 10^{12} \mathrm{~cm}^{-2}$ nearing the intrinsic polarization doping since most (all) surface donor states have been passivated. For $T_{\mathrm{Ar}}=640{ }^{\circ} \mathrm{C}$ and $T_{\mathrm{Ar}}=800{ }^{\circ} \mathrm{C}$ the free hole densities increase to $2.3 \times 10^{13} \mathrm{~cm}^{-2}$ and $1.9 \times 10^{13} \mathrm{~cm}^{-2}$, respectively, as a result of chemical acceptor doping. In all cases, except for the freshly annealed samples, the largest hole mobility parameters are found for the QFS-MLG with $T_{\mathrm{Ar}}=1300{ }^{\circ} \mathrm{C}$. This 
is most likely related to the generally lower free hole density parameters. Note that the free charge mobility (and density) parameters represent average parameters obtained over the entire sample area of $10 \mathrm{~mm} \times 10 \mathrm{~mm}$.

\section{Conclusions}

We have critically reviewed the processes in high-temperature sublimation growth of graphene in Ar atmosphere using closed graphite crucible with emphasis on buffer layer formation and free charge carrier properties of MLG and QFS-MLG on $4 \mathrm{H}-\mathrm{SiC}$. We have explored the effect of introducing Ar at different temperatures, $T_{\mathrm{Ar}}$. We have found that the buffer layer coverage decreases with increasing $T_{\mathrm{Ar}}$ with well-developed buffer layer for $T_{\mathrm{Ar}}=800^{\circ} \mathrm{C}$, while for $T_{\mathrm{Ar}}=1300^{\circ} \mathrm{C}$ the buffer layer is just beginning to form. The observed suppression of buffer layer formation at higher $T_{\mathrm{Ar}}$ is accompanied by surface oxidation of the uncovered regions of the $\mathrm{SiC}$ substrates. A scenario in which oxidation occurs during the annealing process is proposed to explain the peculiar shift of the buffer layer formation to higher temperatures. The latter leads to reduced $s p^{3}$ hybridization content and defect densities in the buffer layer when grown on $n$-type conductive substrates. Growth on SI substrates results in significantly improved structural properties of the buffer layers, which is attributed to a slower graphitization process closer to equilibrium due to the reduced thermal conductivity of the substrate. For SI substrate $T_{\mathrm{Ar}}$ plays a minor role for the $s p^{3}$ hybridization content and defect densities in the buffer layer. A comprehensive study of the free charge density and mobility parameters of MLG and QFS-MLG with $T_{\mathrm{Ar}}=640{ }^{\circ} \mathrm{C}, T_{\mathrm{Ar}}$ $=800{ }^{\circ} \mathrm{C}$ and $T_{\mathrm{Ar}}=1300^{\circ} \mathrm{C}$ and four different environmental conditions: freshly annealed in vacuum, after purging with dry $\mathrm{N}_{2}$ (RH $0 \%$ ) for $\sim 20 \mathrm{~h}$, after purging with moist air (RH $45 \%$ ) for $\sim 18 \mathrm{~h}$ and after ambient exposure for several months, allows us to draw the following conclusions:

(i) successful efficient annealing of donors on and near the $\mathrm{SiC}$ surface can be inferred for MLG grown at $2000{ }^{\circ} \mathrm{C}$ independent of $T_{\mathrm{Ar}}$;

(ii) approximately $45 \mathrm{~h}$ purging with moist air (RH $45 \%$ ) is needed to flip the conductivity of MLG from $n$-type to $p$-type and long term exposure to ambient leads to a saturation of the free hole density at $\sim 2 \times 10^{12} \mathrm{~cm}^{-2}$;

(iii) the highest mobility of MLG is determined for $T_{\mathrm{Ar}}=1300^{\circ} \mathrm{C}$ in both intrinsically $n$-type and ambient $p$-type doped situations. It is suggested that this is a result of reduced interface phonon scattering due to improved interface between MLG and the buffer layer rather than between the buffer layer and the $\mathrm{SiC}$ substrate;

(iv) a free hole density of $\sim 1.0 \times 10^{13} \mathrm{~cm}^{-2}$ is suggested to be the intrinsic value for our QFS-MLG resulting from polarization doping in good agreement with the previously reported value of $8.6 \times 10^{12} \mathrm{~cm}^{-2}$ [60];

(v) $T_{\mathrm{Ar}}$ is found to have a profound effect on the free hole parameters of QFS-MLG. A significantly lower free hole density of $\sim 2 \times 10^{12} \mathrm{~cm}^{-2}$ is found in intrinsic QFS-MLG with $T_{\mathrm{Ar}}=1300^{\circ} \mathrm{C}$, which is attributed to additional surface donor states associated with incomplete buffer formation.

Our findings contribute to establishing a comprehensive picture of high-temperature sublimation growth and provide guidance for growth parameters optimization depending on the targeted application of QFS-MLG and MLG on SiC.

Supplementary Materials: The following are available online at https:/ / www.mdpi.com/2076-3 417/11/4/1891/s1, Figure S1: Representative AFM images and step height distributions of buffer layers grown on $\mathrm{SI} 4 \mathrm{H}-\mathrm{SiC}$ with $T_{\mathrm{Ar}}=800^{\circ} \mathrm{C}$ and $\mathrm{T}_{\mathrm{Ar}}=1300^{\circ} \mathrm{C}$.

Author Contributions: individual contributions of the authors are as follows: conceptualization, V.S. and V.D.; methodology, N.A. and P.K.; software, V.S.; validation, V.S.; formal analysis, V.S. and V.D.; investigation, V.S., N.A., A.A.Z., C.C., I.G.I. and C.B.; resources, R.Y. and V.D.; writing-original draft preparation, V.S. and V.D.; writing-review and editing, V.S., N.A., R.Y., C.C. and V.D.; visualization, V.S. and V.D.; supervision, V.D.; project administration, V.D.; funding acquisition, R.Y. and V.D. All authors have read and agreed to the published version of the manuscript. 
Funding: The authors would like to acknowledge financial support from the Swedish Research Council (VR Contract 2016-00889), the Swedish foundation for strategic research (SSF) under Grants No. FFL12-0181 and No. RIF14-055, the Swedish Government Strategic Research Area in Materials Science on Functional Materials at Linköping University (Faculty Grant SFO Mat LiU No 2009 00971). RY is grateful for financial support by SSF via grant RMA 15-0024.

Acknowledgments: We thank Valdas Jokubavicius for his help with annealing the MLG and QFSMLG samples in vacuum.

Conflicts of Interest: The authors declare no conflict of interest. The funders had no role in the design of the study; in the collection, analyses, or interpretation of data; in the writing of the manuscript, or in the decision to publish the results.

\section{References}

1. Virojanadara, C.; Syväjärvi, M.; Yakimova, R.; Johansson, L.I.; Zakharov, A.A.; Balasubramanian, T. Homogeneous large-area graphene layer growth on $6 \mathrm{H}-\mathrm{SiC}(0001)$. Phys. Rev. B 2008, 78, 245403. [CrossRef]

2. Emtsev, K.V.; Bostwick, A.; Horn, K.; Jobst, J.; Kellogg, G.L.; Ley, L.; McChesney, J.L.; Ohta, T.; Reshanov, S.A.; Röhrl, J.; et al. Towards wafer-size graphene layers by atmospheric pressure graphitization of silicon carbide. Nat. Mater. 2009, 8, $203-207$. [CrossRef]

3. de Heer, W.A.; Berger, C.; Ruan, M.; Sprinkle, M.; Li, X.; Hu, Y.; Zhang, B.; Hankinson, J.; Conrad, E. Large area and structured epitaxial graphene produced by confinement controlled sublimation of silicon carbide. Proc. Natl. Acad. Sci. USA 2011, 108, 16900-16905. [CrossRef] [PubMed]

4. Kruskopf, M.; Momeni Pakdehi, D.; Pierz, K.; Wundrack, S.; Stosch, R.; Dziomba, T.; Götz, M.; Baringhaus, J.; Aprojanz, J.; Tegenkamp, C.; et al. Comeback of epitaxial graphene for electronics: Large-area growth of bilayer-free graphene on SiC. $2 \mathrm{D}$ Mater. 2016, 3, 041002, doi:10.1088/2053-1583/3/4/041002. [CrossRef]

5. Ang, P.K.; Chen, W.; Wee, A.T.S.; Loh, K.P. Solution-gated epitaxial graphene as pH sensor. J. Am. Chem. Soc. 2008, 130, 1439214393. [CrossRef]

6. Lin, Y.M.; Dimitrakopoulos, C.; Jenkins, K.A.; Farmer, D.B.; Chiu, H.Y.; Grill, A.; Avouris, P. 100-GHz transistors from wafer-scale epitaxial graphene. Science 2010, 327, 662-662. [CrossRef]

7. Tzalenchuk, A.; Lara-Avila, S.; Kalaboukhov, A.; Paolillo, S.; Syväjärvi, M.; Yakimova, R.; Kazakova, O.; Janssen, T.J.B.M.; Falko, V.; Kubatkin, S. Towards a quantum resistance standard based on epitaxial graphene. Nat. Nanotechnol. 2010, 5, 186-189. [CrossRef]

8. Lin, Y.M.; Valdes-Garcia, A.; Han, S.J.; Farmer, D.B.; Meric, I.; Sun, Y.; Wu, Y.; Dimitrakopoulos, C.; Grill, A.; Avouris, P.; et al. Wafer-scale graphene integrated circuit. Science 2011, 332, 1294-1297. [CrossRef]

9. Rodner, M.; Bahonjic, J.; Mathisen, M.; Gunnarsson, R.; Ekeroth, S.; Helmersson, U.; Ivanov, I.G.; Yakimova, R.; Eriksson, J. Performance tuning of gas sensors based on epitaxial graphene on silicon carbide. Mater. Des. 2018, 153, 153158.:/ / doi.org/10.1016/j.matdes.2018.04.087. [CrossRef]

10. Seyller, T.; Emtsev, K.V.; Gao, K.; Speck, F.; Ley, L.; Tadich, A.; Broekman, L.; Riley, J.D.; Leckey, R.C.G.; Rader, O.; et al. Structural and electronic properties of graphite layers grown on SiC(0001). Surf. Sci. 2006, 600, 3906-3911. [CrossRef]

11. Riedl, C.; Starke, U.; Bernhardt, J.; Franke, M.; Heinz, K. Structural properties of the graphene-SiC(0001) interface as a key for the preparation of homogeneous large-terrace graphene surfaces. Phys. Rev. B 2007, 76, 245406. [CrossRef]

12. de Heer, W.A.; Berger, C.; Wu, X.; First, P.N.; Conrad, E.H.; Li, X.; Li, T.; Sprinkle, M.; Hass, J.; Sadowski, M.L.; et al. Epitaxial graphene. Solid State Commun. 2007, 143, 92-100. doi:10.1016/j.ssc.2007.04.023. [CrossRef]

13. Gu, G.; Nie, S.; Feenstra, R.M.; Devaty, R.P.; Choyke, W.J.; Chan, W.K.; Kane, M.G. Field effect in epitaxial graphene on a silicon carbide substrate. Appl. Phys. Lett. 2007, 90, 253507. [CrossRef]

14. Hibino, H.; Kageshima, H.; Maeda, F.; Nagase, M.; Kobayashi, Y.; Yamaguchi, H. Microscopic thickness determination of thin graphite films formed on $\mathrm{SiC}$ from quantized oscillation in reflectivity of low-energy electrons. Phys. Rev. B 2008, 77, 075413, doi:10.1103/PhysRevB.77.075413. [CrossRef]

15. Virojanadara, C.; Yakimova, R.; Zakharov, A.A.; Johansson, L.I. Large homogeneous mono-/bi-layer graphene on 6H-SiC(0001) and buffer layer elimination. J. Phys. D Appl. Phys. 2010, 43, 374010. [CrossRef]

16. Dimitrakopoulos, C.; Grill, A.; McArdle, T.J.; Liu, Z.; Wisnieff, R.; Antoniadis, D.A. Effect of SiC wafer miscut angle on the morphology and Hall mobility of epitaxially grown graphene. Appl. Phys. Lett. 2011, 98, 222105. [CrossRef]

17. Kruskopf, M.; Pierz, K.; Wundrack, S.; Stosch, R.; Dziomba, T.; Kalmbach, C.C.; Müller, A.; Baringhaus, J.; Tegenkamp, C.; Ahlers, F.J.; et al. Epitaxial graphene on SiC: Modification of structural and electron transport properties by substrate pretreatment. J. Phys. Condens. Matter 2015, 27, 185303. [CrossRef] [PubMed]

18. Ji, S.H.; Hannon, J.B.; Tromp, R.M.; Perebeinos, V.; Tersoff, J.; Ross, F.M. Atomic-scale transport in epitaxial graphene. Nat. Mater. 2012, 11, 114-119. [CrossRef] [PubMed]

19. Giannazzo, F.; Deretzis, I.; La Magna, A.; Roccaforte, F.; Yakimova, R. Electronic transport at monolayer-bilayer junctions in epitaxial graphene on SiC. Phys. Rev. B 2012, 86, 235422. [CrossRef]

20. Yakimova, R.; Yazdi, G.R.; Iakimov, T.; Eriksson, J.; Darakchieva, V. (Invited) Challenges of Graphene Growth on Silicon Carbide. ECS Trans. 2013, 53, 9-16. [CrossRef] 
21. Darakchieva, V.; Boosalis, A.; Zakharov, A.A.; Hofmann, T.; Schubert, M.; Tiwald, T.E.; Iakimov, T.; Vasiliauskas, R.; Yakimova, R. Large-area microfocal spectroscopic ellipsometry mapping of thickness and electronic properties of epitaxial graphene on Si- and C-face of 3C-SiC(111). Appl. Phys. Lett. 2013, 102, 155411. [CrossRef]

22. Yakimova, R.; Iakimov, T.; Yazdi, G.; Bouhafs, C.; Eriksson, J.; Zakharov, A.; Boosalis, A.; Schubert, M.; Darakchieva, V. Morphological and electronic properties of epitaxial graphene on SiC. Phys. B Condens. Matter 2014, 439, 54-59. doi:10.1016/j.physb.2013.12.048. [CrossRef]

23. Yazdi, G.R.; Vasiliauskas, R.; Iakimov, T.; Zakharov, A.; Syväjärvi, M.; Yakimova, R. Growth of large area monolayer graphene on 3C-SiC and a comparison with other SiC polytypes. Carbon 2013, 57, 477. [CrossRef]

24. Armakavicius, N.; Kühne, P.; Eriksson, J.; Bouhafs, C.; Stanishev, V.; Ivanov, I.G.; Yakimova, R.; Zakharov, A.A.; Al-Temimy, A.; Coletti, C.; et al. Resolving mobility anisotropy in quasi-free-standing epitaxial graphene by terahertz optical Hall effect. Carbon 2021, 172, 248-259.:/ / doi.org/10.1016/j.carbon.2020.09.035. [CrossRef]

25. Momeni Pakdehi, D.; Aprojanz, J.; Sinterhauf, A.; Pierz, K.; Kruskopf, M.; Willke, P.; Baringhaus, J.; Stöckmann, J.; Traeger, G.; Hohls, F; et al. Minimum resistance anisotropy of epitaxial graphene on SiC. ACS Appl. Mater. Interfaces 2018, 10, 6039-6045. [CrossRef]

26. Tromp, R.M.; Hannon, J.B. Thermodynamics and Kinetics of Graphene Growth on SiC(0001). Phys. Rev. Lett. 2009, 102, 106104. [CrossRef]

27. Riedl, C.; Coletti, C.; Starke, U. Structural and electronic properties of epitaxial graphene on SiC(0001) : A review of growth, characterization, transfer doping and hydrogen intercalation. J. Phys. D Appl. Phys. 2010, 43, 374009. [CrossRef]

28. Riedl, C.; Coletti, C.; Iwasaki, T.; Zakharov, A.A.; Starke, U. Quasi-Free-Standing Epitaxial Graphene on SiC Obtained by Hydrogen Intercalation. Phys. Rev. Lett. 2009, 103, 246804. [CrossRef]

29. Forbeaux, I.; Themlin, J.M.; Debever, J.M. Heteroepitaxial graphite on $6 H$ - SiC (0001) : Interface formation through conductionband electronic structure. Phys. Rev. B 1998, 58, 16396-16406. [CrossRef]

30. Kageshima, H.; Hibino, H.; Yamaguchi, H.; Nagase, M. Stability and reactivity of steps in the initial stage of graphene growth on the SiC(0001) surface. Phys. Rev. B 2013, 88, 235405. [CrossRef]

31. Strupinski, W.; Grodecki, K.; Caban, P.; Ciepielewski, P.; Jozwik-Biala, I.; Baranowski, J. Formation mechanism of graphene buffer layer on $\mathrm{SiC}(0001)$. Carbon 2015, 81, 63-72. [CrossRef]

32. Kruskopf, M.; Pierz, K.; Pakdehi, D.M.; Wundrack, S.; Stosch, R.; Bakin, A.; Schumacher, H.W. A morphology study on the epitaxial growth of graphene and its buffer layer. Thin Solid Film. 2018, 659, 7-15. [CrossRef]

33. Wang, T.; Huntzinger, J.R.; Bayle, M.; Roblin, C.; Decams, J.M.; Zahab, A.A.; Contreras, S.; Paillet, M.; Landois, P. Buffer layers inhomogeneity and coupling with epitaxial graphene unravelled by Raman scattering and graphene peeling. Carbon 2020, 163, 224-233. [CrossRef]

34. Momeni Pakdehi, D.; Pierz, K.; Wundrack, S.; Aprojanz, J.; Nguyen, T.T.N.; Dziomba, T.; Hohls, F.; Bakin, A.; Stosch, R.; Tegenkamp, C.; et al. Homogeneous Large-Area Quasi-Free-Standing Monolayer and Bilayer Graphene on SiC. ACS Appl. Nano Mater. 2019, 2, 844-852. doi:10.1021/acsanm.8b02093. [CrossRef]

35. Yakimova, R.; Iakimov, T.; Syväjärvi, M. Process for Growth of Graphene, PCT/SE2011/050328 (2011). U.S. Patent No. 9 150 417, 6 October 2015.

36. Ivanov, I.G.; Hassan, J.U.; Iakimov, T.; Zakharov, A.A.; Yakimova, R.; Janzén, E. Layer-number determination in graphene on SiC by reflectance mapping. Carbon 2014, 77, 492. [CrossRef]

37. Kühne, P.; Armakavicius, N.; Stanishev, V.; Herzinger, C.M.; Schubert, M.; Darakchieva, V. Advanced Terahertz FrequencyDomain Ellipsometry Instrumentation for In Situ and Ex Situ Applications. IEEE Trans. Terahertz Sci. Technol. 2018, 8, 257-270. [CrossRef]

38. Schubert, M.; Kühne, P.; Darakchieva, V.; Hofmann, T. Optical Hall effect-model description: Tutorial. J. Opt. Soc. Am. A 2016, 33, 1553. [CrossRef] [PubMed]

39. Knight, S.; Schöche, S.; Kühne, P.; Hofmann, T.; Darakchieva, V.; Schubert, M. Tunable cavity-enhanced terahertz frequencydomain optical Hall effect. Rev. Sci. Instruments 2020, 91, 083903, doi:10.1063/5.0010267. [CrossRef] [PubMed]

40. Knight, S.; Hofmann, T.; Bouhafs, C.; Armakavicius, N.; Kühne, P.; Stanishev, V.; Ivanov, I.G.; Yakimova, R.; Wimer, S.; Schubert, M.; et al. In-situ terahertz optical Hall effect measurements of ambient effects on free charge carrier properties of epitaxial graphene. Sci. Rep. 2017, 7, 1-8. [CrossRef]

41. Novoselov, K.S.; Geim, A.K.; Morozov, S.V.; Jiang, D.; Katsnelson, M.I.; Grigorieva, I.V.; Dubonos, S.V.; Firsov, A.A. Twodimensional gas of massless Dirac fermions in graphene. Nature 2005, 438, 197-200. doi:10.1038/nature04233. [CrossRef] [PubMed]

42. Fromm, F.; Oliveira, M.H., Jr.; Molina-Sánchez, A.; Hundhausen, M.; Lopes, J.M.J.; Riechert, H.; Wirtz, L.; Seyller, T. Contribution of the buffer layer to the Raman spectrum of epitaxial graphene on SiC(0001). New J. Phys. 2013, 15, 043031, doi:10.1088/13672630/15/4/043031. [CrossRef]

43. Bouhafs, C.; Zakharov, A.A.; Ivanov, I.G.; Giannazzo, F.; Eriksson, J.; Stanishev, V.; Kühne, P.; Iakimov, T.; Hofmann, T.; Schubert, M.; et al. Multi-scale investigation of interface properties, stacking order and decoupling of few layer graphene on $\mathrm{C}$-face $4 \mathrm{H}-\mathrm{SiC}$. Carbon 2017, 116, 722-732. [CrossRef] 
44. Robinson, Z.R.; Jernigan, G.G.; Currie, M.; Hite, J.K.; Bussmann, K.M.; Nyakiti, L.O.; Garces, N.Y.; Nath, A.; Rao, M.V.; Wheeler, V.D.; et al. Challenges to graphene growth on $\mathrm{SiC}(000-1)$ : Substrate effects, hydrogen etching and growth ambient. Carbon 2015, 81, 73-82. [CrossRef]

45. Jokubavicius, V.; Yazdi, G.R.; Ivanov, I.G.; Niu, Y.; Zakharov, A.; Iakimov, T.; Syväjärvi, M.; Yakimova, R. Surface engineering of $\mathrm{SiC}$ via sublimation etching. Appl. Surf. Sci. 2016, 390, 816-822. [CrossRef]

46. Schmeißer, D.; Batchelor, D.; Mikalo, R.; Hoffmann, P.; Lloyd-Spetz, A. Oxide growth on SiC(0001) surfaces. Appl. Surf. Sci. 2001, 184, 340-345. doi:10.1016/S0169-4332(01)00514-1. [CrossRef]

47. Martins Ferreira, E.H.; Moutinho, M.V.O.; Stavale, F.; Lucchese, M.M.; Capaz, R.B.; Achete, C.A.; Jorio, A. Evolution of the Raman spectra from single-, few-, and many-layer graphene with increasing disorder. Phys. Rev. B 2010, 82, 125429. [CrossRef]

48. Ferrari, A.C.; Robertson, J. Interpretation of Raman spectra of disordered and amorphous carbon. Phys. Rev. B 2000, 61, 1409514107. [CrossRef]

49. Berger, C.; Song, Z.; Li, X.; Wu, X.; Brown, N.; Naud, C.; Mayou, D.; Li, T.; Hass, J.; Marchenkov, A.N.; et al. Electronic Confinement and Coherence in Patterned Epitaxial Graphene. Science 2006, 312, 1191-1196. [CrossRef]

50. Ohta, T.; Bostwick, A.; McChesney, J.L.; Seyller, T.; Horn, K.; Rotenberg, E. Interlayer Interaction and Electronic Screening in Multilayer Graphene Investigated with Angle-Resolved Photoemission Spectroscopy. Phys. Rev. Lett. 2007, 98, 206802. [CrossRef]

51. Emtsev, K.V.; Speck, F.; Seyller, T.; Ley, L.; Riley, J.D. Interaction, growth, and ordering of epitaxial graphene on SiC $\{0001\}$ surfaces: A comparative photoelectron spectroscopy study. Phys. Rev. B 2008, 77, 155303. [CrossRef]

52. Sidorov, A.N.; Gaskill, K.; Buongiorno Nardelli, M.; Tedesco, J.L.; Myers-Ward, R.L.; Eddy, C.R.; Jayasekera, T.; Kim, K.W.; Jayasingha, R.; Sherehiy, A.; et al. Charge transfer equilibria in ambient-exposed epitaxial graphene on (000 - 1) 6H-SiC. J. Appl. Phys. 2012, 111, 113706, doi:10.1063/1.4725413. [CrossRef]

53. Tedesco, J.L.; VanMil, B.L.; Myers-Ward, R.L.; McCrate, J.M.; Kitt, S.A.; Campbell, P.M.; Jernigan, G.G.; Culbertson, J.C.; Eddy, C.R.; Gaskill, D.K. Hall effect mobility of epitaxial graphene grown on silicon carbide. Appl. Phys. Lett. 2009, 95, 235406. [CrossRef]

54. Armakavicius, N.; Bouhafs, C.; Stanishev, V.; Kühne, P.; Yakimova, R.; Knight, S.; Hofmann, T.; Schubert, M.; Darakchieva, V. Cavity-enhanced optical Hall effect in epitaxial graphene detected at terahertz frequencies. Appl. Surf. Sci. 2017, 421, 357360.:/ /dx.doi.org/10.1016/j.apsusc.2016.10.023. [CrossRef]

55. Kopylov, S.; Tzalenchuk, A.; Kubatkin, S.; Fal'ko, V.I. Charge transfer between epitaxial graphene and silicon carbide. Appl. Phys. Lett. 2010, 97, 112109, doi:10.1063/1.3487782. [CrossRef]

56. Fratini, S.; Guinea, F. Substrate-limited electron dynamics in graphene. Phys. Rev. B 2008, 77, 195415. [CrossRef]

57. Tanabe, S.; Sekine, Y.; Kageshima, H.; Nagase, M.; Hibino, H. Carrier transport mechanism in graphene on SiC(0001). Phys. Rev. B 2011, 84, 115458. [CrossRef]

58. Lisesivdin, S.; Atmaca, G.; Arslan, E.; Çakmakyapan, S.; Kazar, Ö.; Bütün, S.; Ul-Hassan, J.; Janzén, E.; Özbay, E. Extraction and scattering analyses of 2D and bulk carriers in epitaxial graphene-on-SiC structure. Phys. E Low-Dimens. Syst. Nanostructures 2014, 63, 87-92. [CrossRef]

59. Ristein, J.; Mammadov, S.; Seyller, T. Origin of Doping in Quasi-Free-Standing Graphene on Silicon Carbide. Phys. Rev. Lett. 2012, 108, 246104, doi:10.1103/PhysRevLett.108.246104. [CrossRef]

60. Mammadov, S.; Ristein, J.; Koch, R.J.; Ostler, M.; Raidel, C.; Wanke, M.; Vasiliauskas, R.; Yakimova, R.; Seyller, T. Polarization doping of graphene on silicon carbide. 2D Mater. 2014, 1, 035003. [CrossRef] 